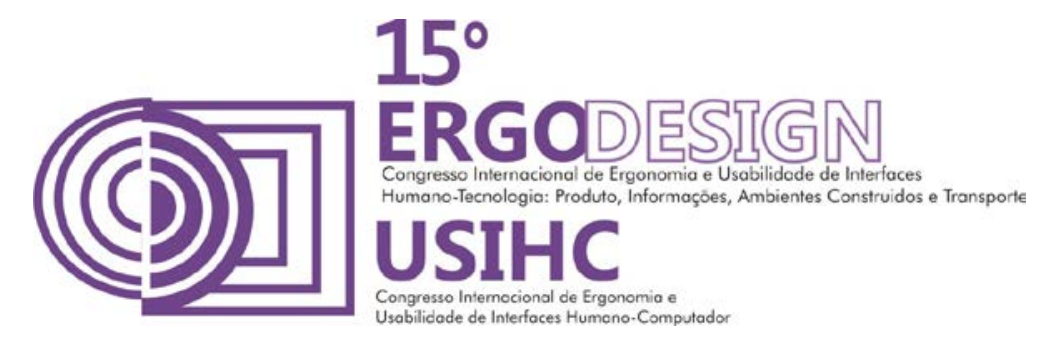

\title{
ERGONOMIA E COMÉRCIO INFORMAL: REDESIGN DE UM POSTO DE VENDA DE CASES PARA CELULAR
}

\author{
MELO, Wynne (1); \\ VERISSIMO, Bruno (2) \\ BARROS, Bruno (3); \\ (1) Universidade Federal de Pernambuco, Graduanda \\ e-mail:wynne melo@hotmail.com \\ (2) Universidade Federal de Pernambuco, Graduando \\ e-mail:bruno verissimo@live.com \\ (3) Universidade Federal de Pernambuco, Mestre \\ e-mail:barros bruno@hotmail.com
}

\begin{abstract}
RESUMO
O mercado informal se configura como um grande setor que envolve diretamente seres humanos em postos de trabalho improvisados. Desta forma, a referente pesquisa consistiu na análise e proposições de melhoria do posto de trabalho de um vendedor ambulante de cases de celular, tendo como princípios dados antropométricos, biomecânicos, ambiência de dados coletados no local (assim como questionários e escala de corllet). A base Metodológica foi a Intervenção Ergonomizadora do Sistema Humano-TarefaMáquina (SHTM). Com os problemas acionais, posturais, naturais e acidentais identificados, e uma comparação com os estudos apresentados, estabeleceu-se um projeto de redesign ergonômico para 0 posto, levando em consideração a melhoria do posto de trabalho como um todo.
\end{abstract}

\section{ABSTRACT}

The informal market has been configured as a large sector and that directly involves human beings in makeshift jobs. Thus, the related research focused on the analysis and improvement of propositions of the post from a street vendor of mobile cases, with the principles and anthropometric data, biomechanical, and ambience collected on site (as well as questionnaires and corllet scale). The methodological basis was the Ergonomics Intervention Human Task-Machine System (HTMS). With ational, postural, natural and accidental problems identified, and a comparison with the studies presented, settled an ergonomic redesign project for the position, taking into account the improvement of the workplace as a whole. 


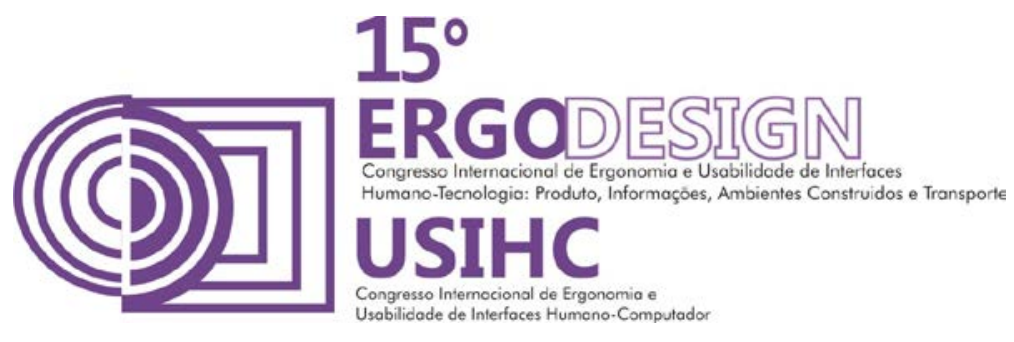

\section{INTRODUÇÃO}

Tendo em vista a complexidade crescente do desempenho humano no trabalho e as extensas jornadas de trabalho, a Ergonomia busca adequar a interface humano-máquina, de modo que as tarefas, postos de trabalho, produtos, ambientes e sistemas tornem-se compatíveis com as necessidades, habilidades e limitações das pessoas.

Com a proposta de redesign do posto de trabalho do vendedor ambulante de cases para celular, esta pesquisa atendeu à solicitação de trabalho final da disciplina de Ergonomia do Produto do curso de Design da Universidade Federal de Pernambuco, que requisitou o redesign ergonômico de um produto ou posto de trabalho. O posto de trabalho escolhido, uma estrutura utilizada por vendedores de artigos para celular no centro da cidade de Caruaru, sofreu um redesign com a aplicação de dados biomecânicos e antropométricos a partir de informações obtidas através de pesquisas e entrevistas com os trabalhadores, o que possibilitou uma intervenção focada no conforto e segurança para os usuários na execução do trabalho.

Baseando-se nos resultados dos questionários, que apontaram os principais problemas e desconfortos causados pelos instrumentos de trabalho, a proposta de redesign desenvolvida promoveu uma reorganização do posto de trabalho com a modificação dos objetos utilizados para exposição dos produtos, introduzindo um expositor retrátil, e conferindo a ele também a capacidade de armazenagem e locomoção, e a modificação do assento, antes muito desconfortável por ser baixo e não possuir encosto.

\section{FUNDAMENTAÇÃO TEÓRICA}

Quem nunca foi abordado nas ruas por pessoas comercializando DVDs, óculos de sol, DVDs, sapatos, roupas, entre outros produtos falsificados? A visão do "camelô" é a mais corriqueira quando se refere à economia informal. Contudo, sua abrangência é bem mais ampla e pode ser caracterizada por uma gama de atividades econômicas concretizadas sem a ação de registros oficiais, tal qual emissão de notas fiscais, assinatura de carteira de trabalho. Dentro deste contexto encontra-se o posto de trabalho do vendedor ambulante de cases para celular analisado nesta referente pesquisa (figura 1).

Localizado na calçada de uma avenida de grande movimentação, sua mercadoria (que, além de contar com cases para celular, também possui controles remotos e antenas de televisão) fica fixada em três grades de ferro expostas na parede lateral de uma loja. Duas das grades possuem $1,70 \mathrm{~m}$ de altura, a outra possui apenas 70 centímetros de altura e são presas à parede por um prego, dando um total de $2,40 \mathrm{~m}$ de altura. As grades são montadas diariamente pela proprietária e, fora do horário comercial, as mesmas são armazenadas em uma pequena loja próxima. As mercadorias são expostas ao ar livre, sujeitas a chuva ou sol forte, com temperaturas que, de acordo com medições feitas no local, chegam a 31․ Também foi aferido no local o nível de luminância, que alcançou 272 lux no fim da manhã, sendo reduzido no final da tarde, o que atrapalha pois a iluminação se torna insuficiente. 

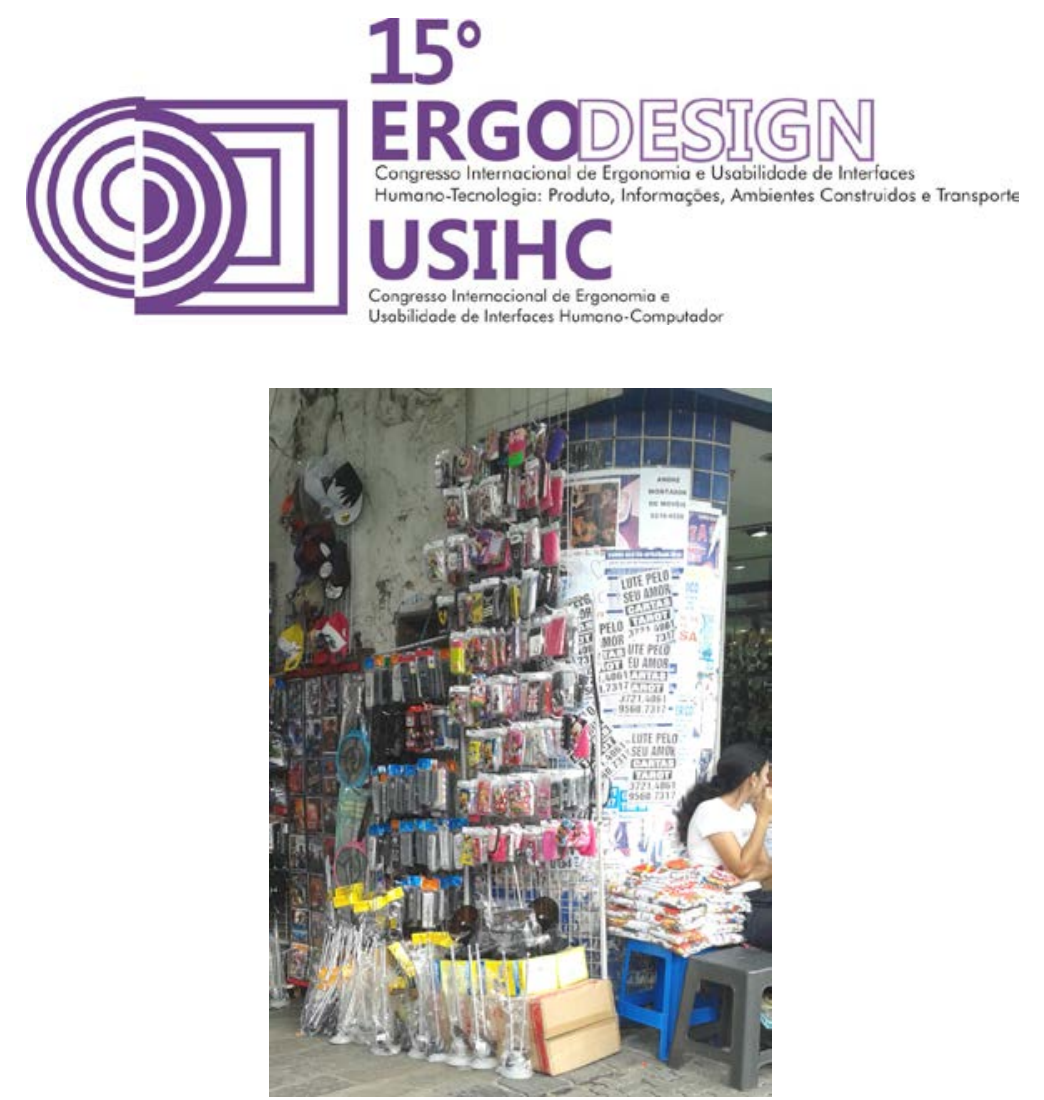

Figura 1 - Posto de trabalho analisado

Viu-se que a vendedora passa a maior parte do tempo sentada num banco de plástico sem encosto, ficando de pé quando se torna necessário o atendimento de clientes. Os cases para aparelhos celulares ficam na grade superior, mais alta, exigindo um esforço maior para alcance, o que faz com que, em alguns casos, seja necessário retirar a grade da parede para aquisição das mercadorias. Seu trabalho pode ser considerado estático, uma vez que ela mantém uma determinada posição durante a maior parte do tempo, exigindo assim concentração contínua de alguns músculos.

\subsection{Dados antropométricos e biomecânicos relacionados ao produto}

Segundo Panero e Zelnik (2013), a antropometria é a ciência que trata especificamente das medidas do corpo humano para determinar diferenças em indivíduos e grupos. "Os dados antropométricos definem as medições de tamanho, peso e proporção do corpo humano aplicáveis a um correto dimensionamento de projeto de produtos, equipamentos e postos de trabalho" (SOARES \& MORAES, 2005). Baseado nessas informações, tende a projetar um ambiente de trabalho que se adeque as medidas e necessidades humanas, provendo assim maior conforto e segurança ao nosso usuário.

Para o posto de trabalho aqui estudado e sua respectiva usuária, dados antropométricos fornecidos por PANERO e ZELNIK (2005) estabelecem que a altura máxima de prateleiras para exposição e armazenamento de produtos, para pessoas do sexo feminino é de $167,6 \mathrm{~cm}$, devendo atender às dimensões de alcance vertical de apreensão, assim como a altura dos olhos; e as dimensões para cadeiras são: $35,6 \mathrm{~cm}$ de altura do assento; $45,4 \mathrm{~cm}$ de profundidade do assento; $43,9 \mathrm{~cm}$ de largura do assento; $63,5 \mathrm{~cm}$ de altura do encosto; $23,9 \mathrm{~cm}$ de altura dos apoios para braços; e 49,0 cm de espaçamento dos apoios para braços.

Também tornou-se necessária uma análise relativa à Biomecânica Ocupacional, que pode ser caracterizada pelo estudo da relação física do trabalhador com ferramentas, máquinas e materiais, objetivando melhorar o seu desempenho, ao mesmo tempo em que minimiza os 


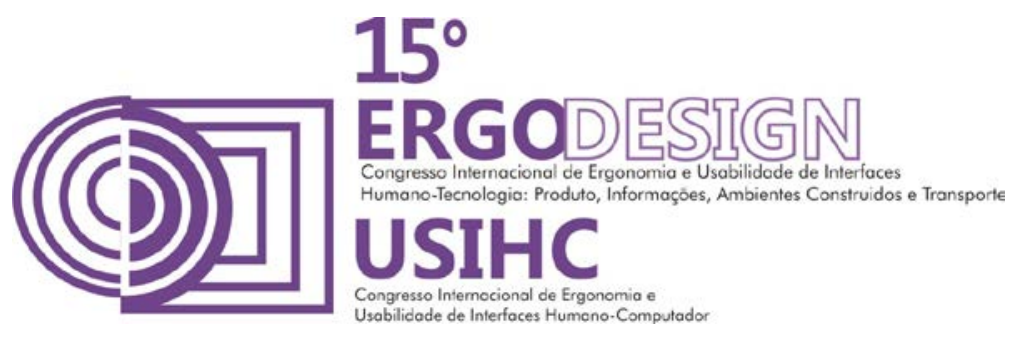

riscos de acometimentos de lesões músculo/esqueléticas (CHAFFIN, ANDERSSON \& MARTIN, 2001). O fato é que muitas vezes ocorre das pessoas tentarem se adaptar a suas ferramentas e locais de trabalho causando assim problemas sérios a sua saúde, pois "muitos produtos e postos de trabalho inadequados provocam estresses musculares, dores e fadiga" (IIDA, 2005).

Segundo Löbach (2001): "o design industrial é o processo de adaptação dos produtos de uso, fabricados industrialmente, às necessidades físicas e psíquicas dos usuários ou grupos de usuários." O local e ferramentas de trabalho da vendedora de cases para celular é uma nítida adaptação de usuário para o produto, sendo assim, devemos levar em consideração que produtos e locais de trabalho devem ser projetados visando o usuário, a fim de evitar danos, como LER e DORTs.

De acordo com o Instituto Nacional de Seguro Social (INSS) as Lesões por Esforços Repetitivos (LER) e Doenças Osteomusculares Relacionadas ao Trabalho (DORT) ocorrem por três fatores, são eles: o uso repetitivo de grupos musculares, uso forçado de grupos musculares e manutenção de postura inadequada. No caso aqui analisado os problemas estão relacionados à manutenção de postura inadequada e trabalho estático, o que pode vir a ocasionar DORTs.

Identificamos a possível incidência de três tipos de DORTs no posto analisado, decorrentes do uso prolongado do posto em questão. A primeira delas é a Síndrome do Túnel do Carpo, causada pela pressão repetitiva e stress sobre os tendões, especialmente se as mãos se inclinam na altura do punho. Os sintomas identificados, os quais levaram a eleição deste risco foram a dor, formigamento e insensibilidade causados pela pressão da bainha do tendão inchado sobre o nervo medial. O risco desta DORT nos fez atentar para a relevância de ferramentas e estruturas de trabalho que possam ser usadas com as mãos na posição neutra.

O segundo risco de DORT identificado foi a Doença Cervicobraquial, caracterizado pela compressão dos nervos e vasos sanguíneos entre o pescoço e os ombros. A vendedora apresentou dores na região pela frequência com que eleva os membros superiores para aquisição dos artefatos de venda. Este risco nos fez atentar para o estudo de uma maneira de se evitar posturas que requeiram frequentes alcances acima do nível dos ombros.

Por fim, também foi identificado o risco de Bursite, uma inflamação das bursas devido ao enrijecimento dos tendões, causado pelo esforço sem recuperação. A vendedora alegou dor durante o movimento da articulação dos ombros. Este risco nos fez atentar para o estudo da redução da força e frequência do movimento, além de evitar posição desconfortável dos membros superiores.

\section{PROCEDIMENTOS METODOLÓGICOS ADOTADOS}

\subsection{Apreciação Ergonômica}

A apreciação ergonômica é uma fase de mapeamento dos problemas ergonômicos da empresa. Nesta fase é feita a sistematização do sistema humano-tarefa-máquina e a delimitação dos problemas. Esta fase é de observações, entrevistas e registros dos operadores no seu local de trabalho, e termina com o parecer ergonômico, que é a apresentação ilustrada dos problemas e disfunções do sistema humano-tarefa-máquina. 


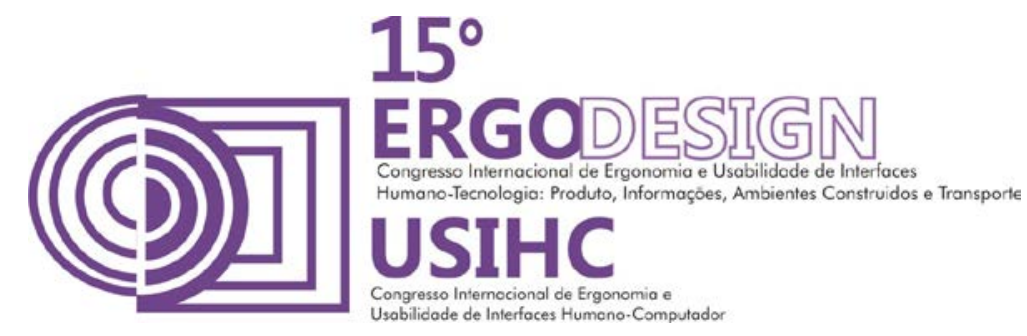

O estudo de caso nos permitiu apontar diversos problemas do posto de venda de cases que é o nosso sistema alvo. Dentre os problemas elencados podemos citar: a falta de encosto do assento, altura do assento inferior à recomendada e inexistência de acolchoado, a altura das grades para exposição, que comporta parte da mercadoria fora do envelope de alcance, a desorganização do ambiente físico.

A figura 2 representa a posição serial do sistema alvo (posto de venda de cases) para melhor compreensão do ambiente de sistema e os elementos que a compõem.

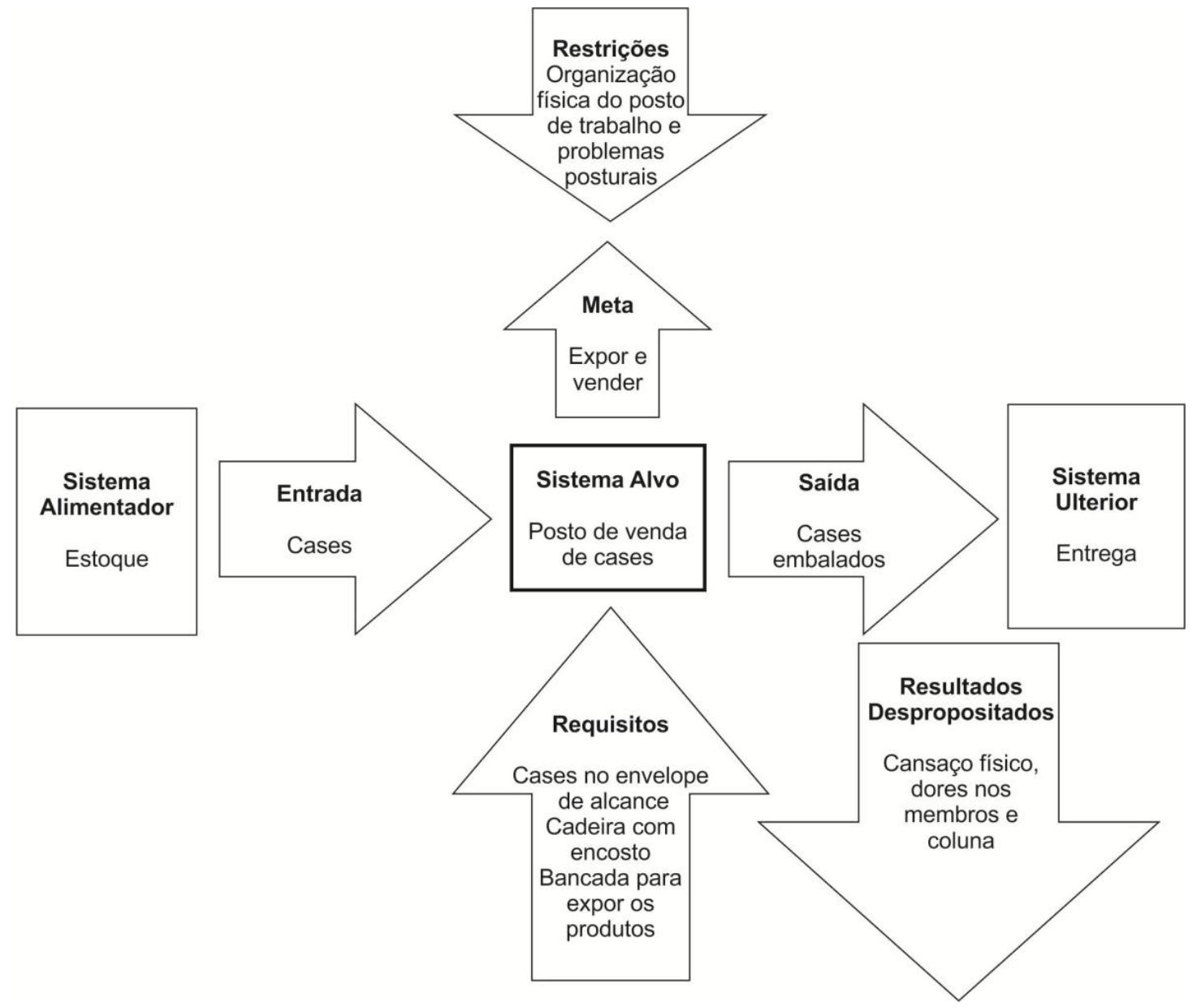

Figura 2 : Caracterização e posição serial do posto de venda de cases.

A figura 3, traz a modelagem comunicacional do sistema Humano-Tarefa-Máquina, que aborda questões de transmissão de informações, os sentidos humanos envolvidos, respostas humanas, deslocamentos, posturas e ações acionadas na execução do trabalho. 

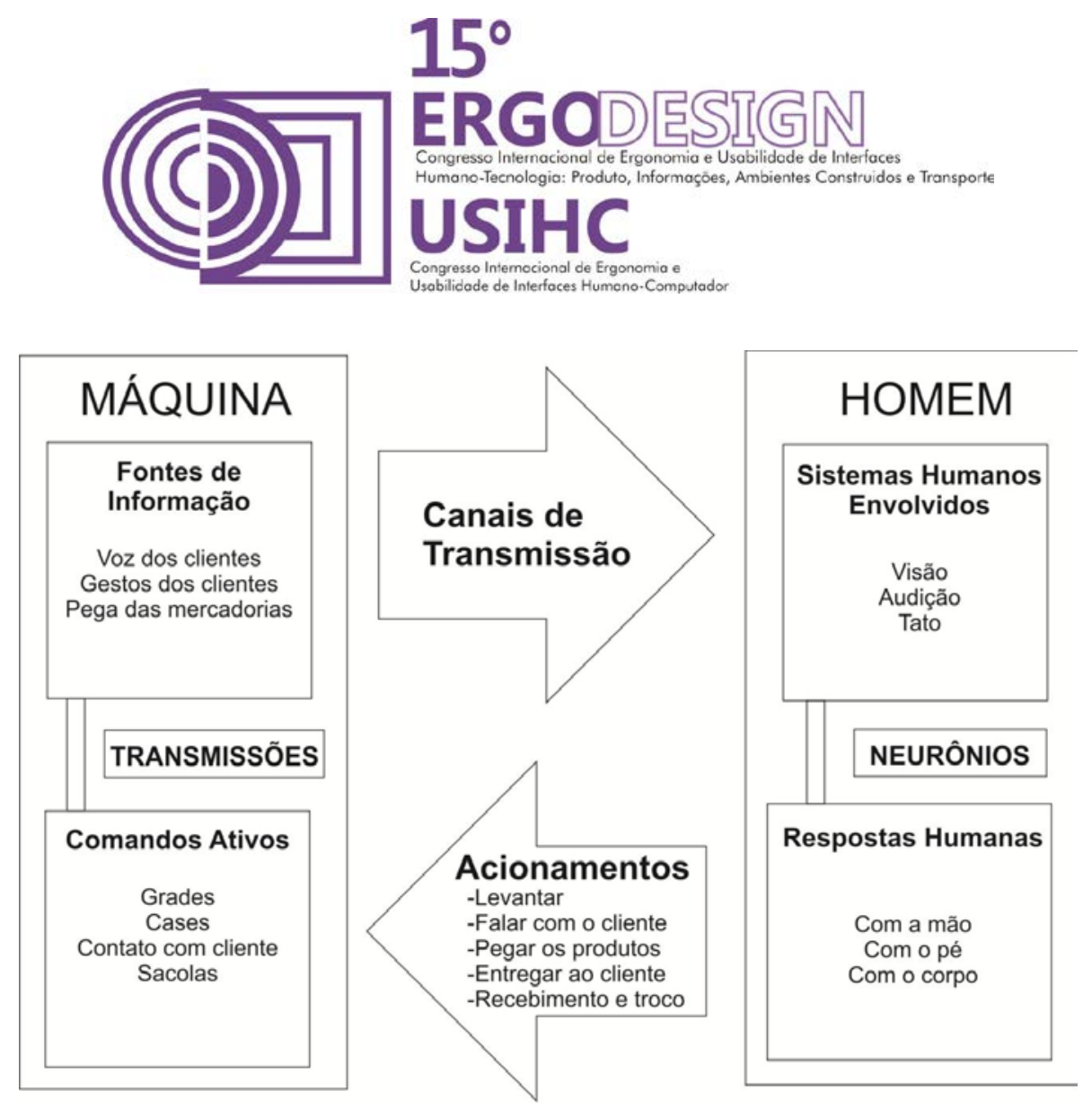

Figura 3 - Modelagem comunicacional do sistema para o posto de trabalho da vendedora de cases para celular.

Com base nas informações levantadas e problemas potenciais diagnosticados na apreciação ergonômica, verificamos a necessidade de uma intervenção ergonômica que melhore as condições e otimize as relações na interface operador/sistema do posto de trabalho aqui estudado. A partir de uma análise dos problemas encontrados, buscamos produzir um redesign que atenda da melhor maneira possível às necessidades do usuário em questão.

\subsection{Aplicação de Questionário}

O questionário foi aplicado a uma única vendedora que trabalha dentro do ambiente de estudo. As perguntas foram aplicadas pela manhã em torno das 10:00 horas, horário de grande movimento no centro da cidade, por conta disto a entrevista foi feita com uma breve conversa.

A pesquisa foi dividida em quatros partes: Agentes Contribuintes, Agentes Fisiológicos, Agentes Ambientais e Agentes Psicossociais. Primeira parte são dados pessoais, como idade, peso, estado civil, local onde mora, entre outros. A segunda parte corresponde a perguntas sobre as condições físicas do respondente, como doenças, medicamentos, dores, desconforto. A terceira parte possui questões onde aborda os equipamentos em ambiente de trabalho, como opinião sobre o mobiliário e o próprio ambiente de trabalho. E a última parte traz perguntas sobre 0 ambiente organizacional no trabalho, como satisfação com a escala de trabalho, se tem passado por problemas ultimamente. 


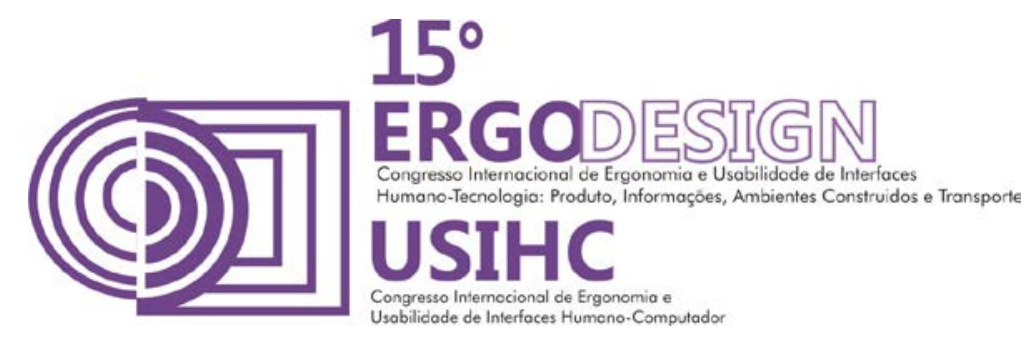

\subsection{Escala de Corllet}

O questionário da Escala de Corllet foi aplicado com o intuito de saber quais os desconfortos e dores decorrentes das atividades realizadas pela vendedora no posto de trabalho. A escala de Corllet é um diagrama onde divide o corpo humano em segmentos diversos facilitando a localização em áreas no qual os trabalhadores sentem dores. Munido deste diagrama, 0 ergonomista entrevista os trabalhadores no começo e final de um período de trabalho, pedindo para que eles apontarem regiões onde sentem dores, em seguida pede-se para que avaliem subjetivamente o grau de desconforto que sentem em cada um dos segmentos indicados no diagrama. O índice de desconforto é classificado em cincos níveis, que varia de um para "extremamente confortável" até o nível cinco, "extremamente desconfortável".

Sendo assim, o questionário foi respondido inicialmente às 8 horas da manhã, antes do início da jornada de trabalho, quando a vendedora ambulante geralmente chega ao local; e novamente às 17 horas da tarde próximo ao fim de expediente. Tendo assim respondido o questionário, avaliamos as dores causadas pelas atividades feitas no local de trabalho.

\section{RESULTADOS}

\subsection{Questionário}

O questionário foi aplicado com o objetivo de conhecermos mais sobre a vendedora, suas opiniões sobre o local de trabalho e suas reclamações com o mesmo, levando em consideração dores e desconforto. A usuária tem 38 anos de idade e trabalha como vendedora ambulante há quatro anos. Além dos cases de celular que vende, também exerce as atividades domésticas básicas em sua casa. Ela trabalha em horário comercial, de acordo com o funcionamento das lojas da rua, e almoça no próprio local de trabalho, muitas vezes sendo auxiliada por outros vendedores ambulantes, caso apareça cliente nos horários que ela estiver almoçando.

De acordo com as respostas do questionário, verificou-se que, durante a jornada de trabalho, a vendedora sente dores nos ombros, devido à má postura ao sentar no banquinho sem encosto. Ainda apresentou dores nas costas (médio e superior), também devido a esse fator do banquinho sem encosto; no quadril, nas coxas e pernas. Segundo o relato da entrevistada, os incômodos no punho e braço são mais evidentes no membro superior direito do que no esquerdo, devido ao esforço maior para pegar as cases nas grades.

A usuária se revelou deveras insatisfeita com seu local de trabalho e considera o banquinho em que senta desconfortável e ruim. A usuária considera satisfatórias as grades de exposição das mercadorias, mas acha o local quente e exposto demais as mudanças climáticas. Ela afirmou não ter noção de quantas peças passam por sua mão diariamente, considera isso relativo e costuma se dar bem com os demais vendedores ambulantes que trabalham próximo ao seu posto de trabalho. 


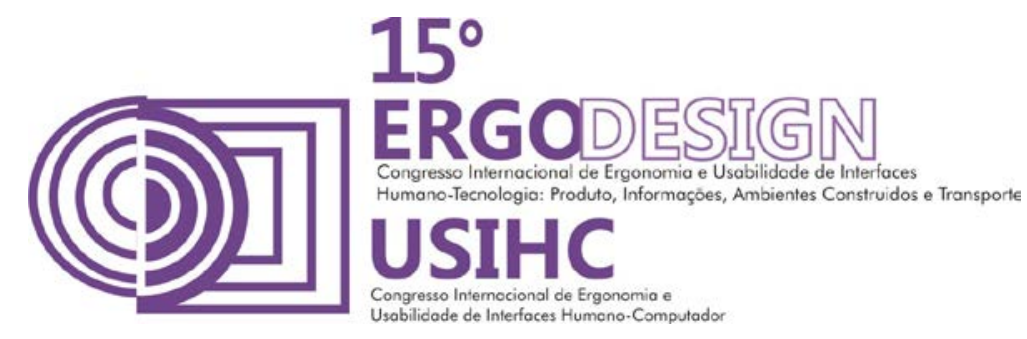

\subsection{Escala de Corlett}

A primeira avaliação da escala de corllet foi feita logo após a chegada da trabalhadora no posto de trabalho, no centro da cidade de Caruaru - PE, em torno das 7 h40 da manhã, a usuária apresentava incômodos de 1 a 4, principalmente na região das costas, ombro, nuca, pescoço e pernas. Na segunda e última avaliação, que foi feita logo após seu expediente de trabalho, em torno das $17 \mathrm{~h}$, a maioria das regiões que foram avaliadas no primeiro expediente tiveram o nível de desconforto acentuados, passando a chegar em uma escala de 3 a 5, principalmente nas regiões das costas superior, costas médio, costas inferior, pescoço, membros superiores, membros inferiores, além de dores no punho esquerdo e direito. Nota-se novamente certos incômodos por parte do banquinho, baixo e sem encosto, gerando posições erradas ao sentar e incômodo na parte das costas, ombro e nuca.

\subsection{Problematização Ergonômica}

No posto de trabalho, foram observados diversos problemas que podem acarretar lesões para a usuária, bem como problema acidental, postural, natural e acional.

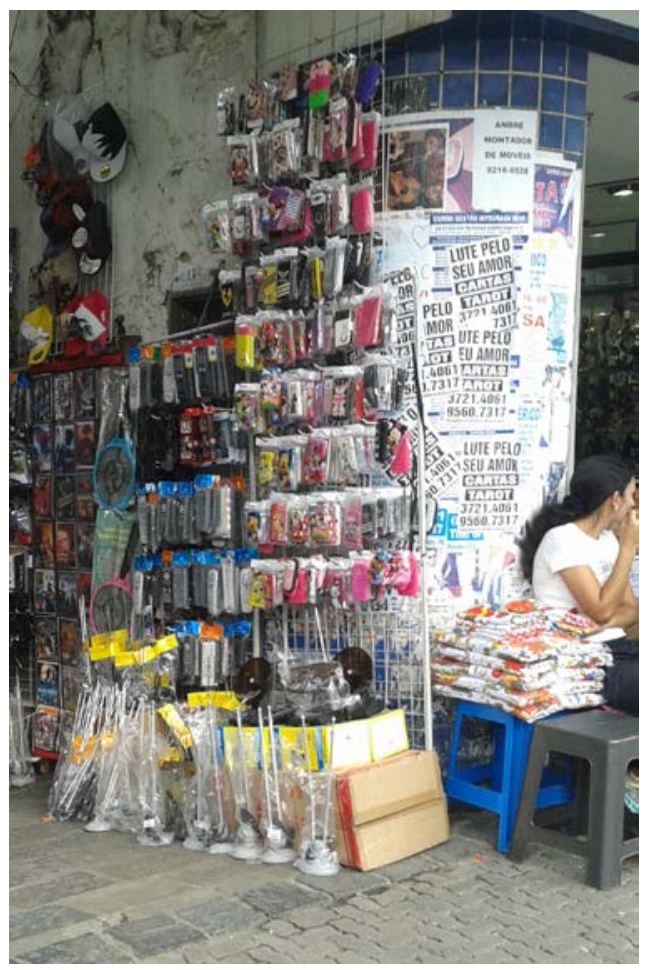

Figura 4 : Posto de trabalho. Fonte: Acervo próprio.

Como podemos observar na figura 4, identificamos problema acidental na grade mal posicionada na parede, através de um pequeno prego, correndo o risco de queda da própria machucando o usuário. O problema postural pode ser identificado na vendedora, postura imprópria da coluna vertebral devido ao fato do banquinho não possuir encosto. Essa 


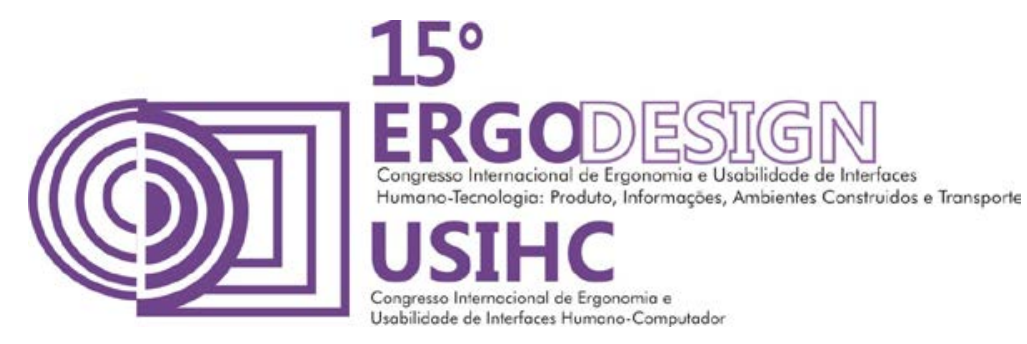

postura pode causar dores na coluna vertebral e ombros. Ainda foram observados problemas naturais, pois o posto de trabalho fica localizado numa rua sem proteção contra o sol causando excessiva exposição as mudanças climáticas, podendo causar danos à saúde da pele do usuário, se exposto por longo período de tempo. E, por fim, encontramos um problema acional na forma de manusear os cases na grade, membro superior elevado acima do ombro, onde ocorre a compressão dos nervos e vasos sanguíneos entre o pescoço e os ombros, podendo causar, a longo prazo, doença cervicobraquial se executado movimento repetitivo contínuo durante o horário de trabalho.

\subsection{Lista de Recomendações Ergonômicas}

* Reorganizar o ambiente de trabalho;

* Otimizar o assento, para evitar desconforto;

* Alterar a estrutura de expor a mercadoria, mantendo os produtos no campo de alcance manual e visual da usuária e dos clientes;

\subsection{Etapas de Criação do Produto}

Nas etapas de criação do produto atentou-se para os problemas encontrados pelo levantamento de dados, afim de fazer uma intervenção eficaz e satisfatória no posto de trabalho. Focado nisso, levamos em conta as principais queixas da usuária, e com base nessas informações, observou-se as necessidades de intervir ergonomicamente no banco que era muito baixo e sem encosto, nas grades de expor a mercadoria que possuía partes muito altas, dificultando a pega dos produtos na parte superior, e no arranjo físico dos elementos do posto de trabalho. Iniciamos a geração de ideias com esboços e, posteriormente, selecionamos e aperfeiçoamos a melhor solução encontrada, e a partir daí produzimos o redesign.

\subsection{Materiais}

Os materiais selecionados para a modificação do posto de trabalho foram: alumínio para o expositor retrátil e para o tubo para transporte, por possuir rigidez e facilidade de retração; MDF revestido para as partes do balcão locomotivo, tais como a parte de gavetas e prateleiras de armazenamento, por ser resistente e leve; e madeira para a cadeira dobrável, por oferecer uma maior resistência e segurança.

\section{7. $\quad$ Apresentação do Partido Projetual}

Para o projeto de redesign foi pensado num posto de trabalho em formato retangular de MDF revestido, medindo $1,56 \mathrm{~m}$ de altura por $1 \mathrm{~m}$ de comprimento e $32 \mathrm{~cm}$ de largura, que facilita na condução do mesmo já que ele possui duas rodas na parte inferior traseira e um tubo de alumínio na parte posterior, para locomoção, como visto na figura 5. 

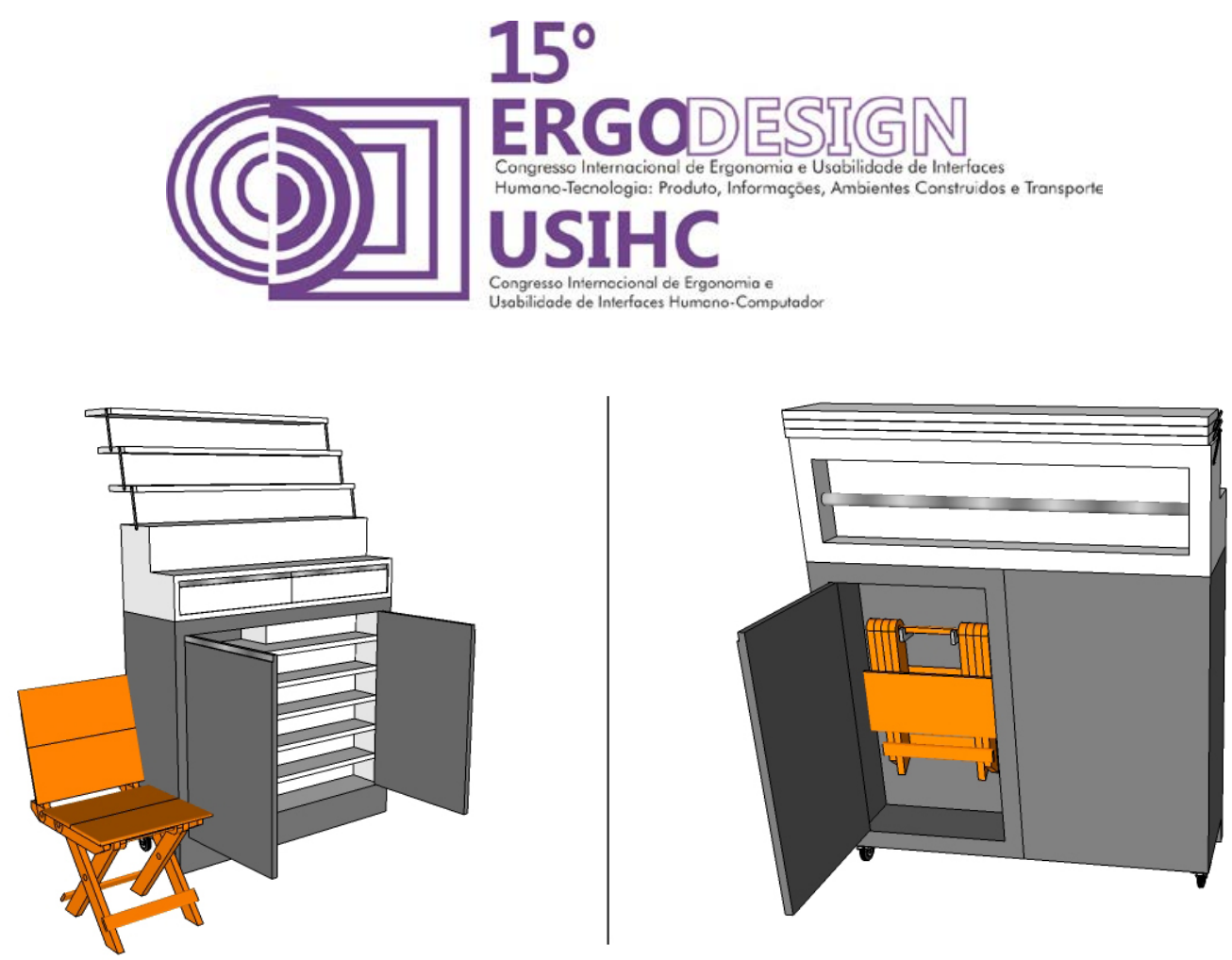

Figura 5: Perspectiva frontal e posterior do esquema do posto de trabalho sugerido (aberto para funcionamento e fechado para armazenamento e locomoção).

No rendering da figura 5, é possível ter uma visão clara de como o posto de trabalho será produzido: gavetas e portas na bancada de MDF revestido para armazenamento dos cases, e para a parte de cima tomamos como inspiração as caixas de ferramentas que possuem estojos retráteis e projetamos um expositor retrátil com três prateleiras para exposição dos cases, podendo estar aberto nos horários de uso e fechado para locomoção do balcão.

O posto de trabalho, aqui apresentado pelo rendering, também possui um banco no formato dobrável, que ficará preso à parte de trás da bancada, em um gancho para suporte do mesmo. Esse banco será produzido em madeira resistente e possuirá as medidas antropométricas adequadas para proporcionar a segurança da usuária.

\subsection{Desenho Técnico em Cotas com Dimensionamento Geral}
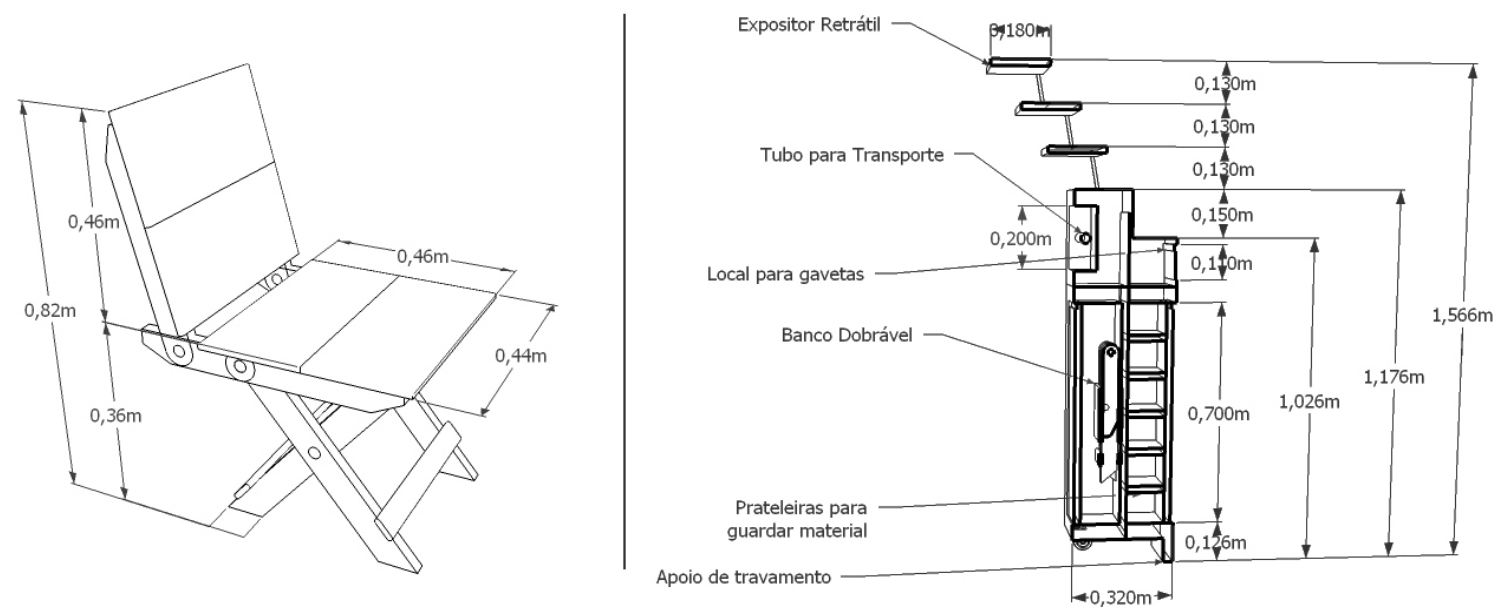

Figura 6: Cadeira dobrável em perspectiva com cotas. Posto em corte transversal com cotas. 


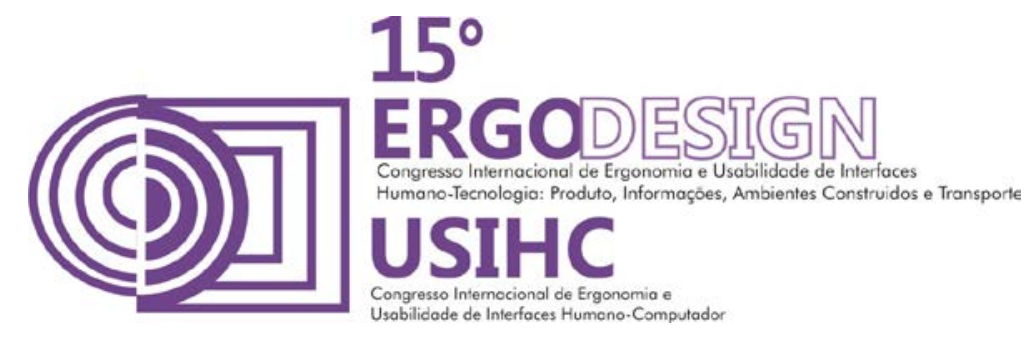

A perspectiva com cotas da figura 6 mostra o banco dobrável projetado nas medidas antropométricas levando em consideração a usuária do produto.

Também na figura 6 , temos um corte transversal com cotas do balcão locomotivo. 0 balcão possui uma altura total, com expositor retrátil aberto, de $1,56 \mathrm{~m}$ que atende às medidas estabelecidas para prateleiras de exposição e armazenamento de produto, para pessoas do sexo feminino. O balcão também possui uma altura ideal para movimentação de pegas na hora de colher cases das gavetas ou portas frontais, além do expositor retrátil estar no campo de visão tanto da vendedora ambulante como do cliente.

Na vista frontal com cotas da figura 7, é perceptível o campo de visão completo do balcão assim como suas prateleiras internas com $10 \mathrm{~cm}$ de espaçamento entre uma e outra.

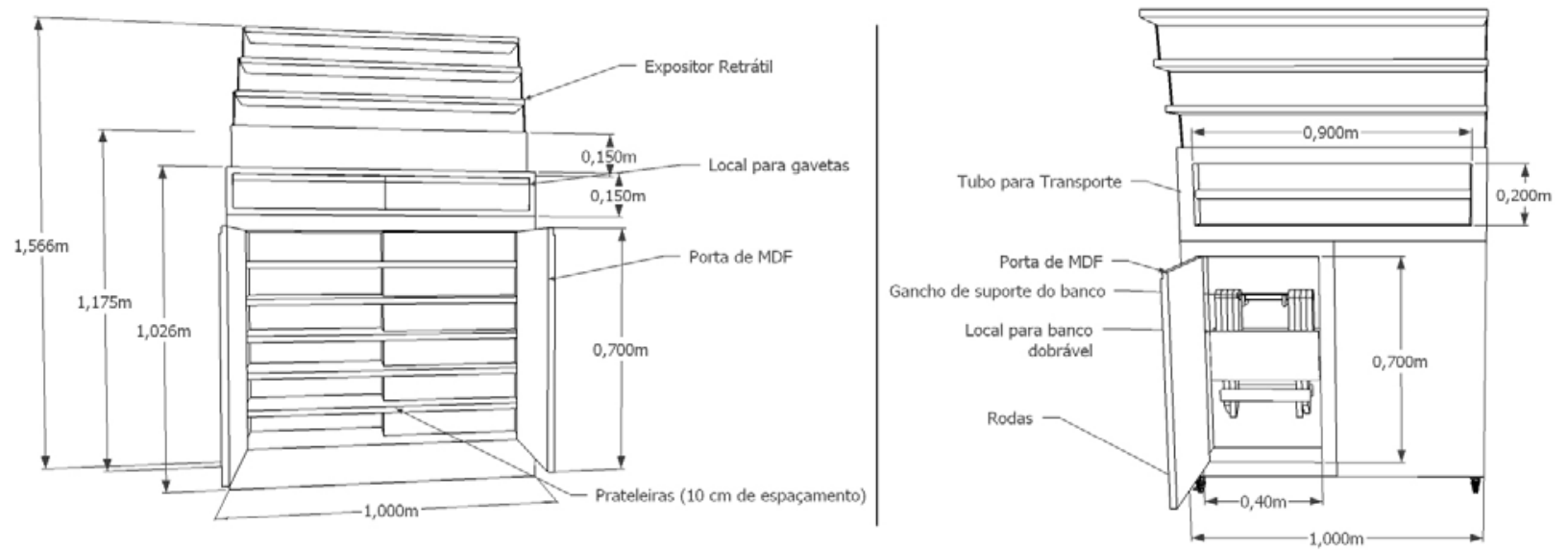

Figura 7 - Vista frontal com cotas. Vista posterior com cotas.

Ainda na figura 7, é representado uma vista posterior, onde nota-se o tubo para transporte do balcão como um "carrinho de supermercado"; assim como a porta posterior aberta com a cadeira dobrável encaixada nos ganchos de suporte, a abertura possui $70 \mathrm{~cm}$ de altura por $40 \mathrm{~cm}$ de largura para armazenamento completo da mesma.

\section{CONCLUSÕES}

Concluído o redesign do produto, pudemos observar com mais clareza como o espaço e os instrumentos de trabalho que a nossa usuária desfrutava eram perceptivelmente fora dos padrões ergonômicos para que um trabalhador pudesse exercer sua função num ambiente confortável e sem oferecer riscos graves à saúde.

Um dos principais pontos negativos notados na antiga configuração do posto de trabalho era a dificuldade de transporte dos materiais até o local, onde a usuária precisava depositar seu material e produto de trabalho dentro de uma loja de outra pessoa, por não ter condições de fazer o transporte dos mesmos de sua casa até o lugar em que comercializava as cases de celular. A maneira como as grades ficavam presas na parede apenas por um prego e a forma desorganizada com que as cases eram distribuídas também eram empecilhos que dificultavam na agilidade do processo de venda, como também ofereciam riscos de acidentes, por estarem 


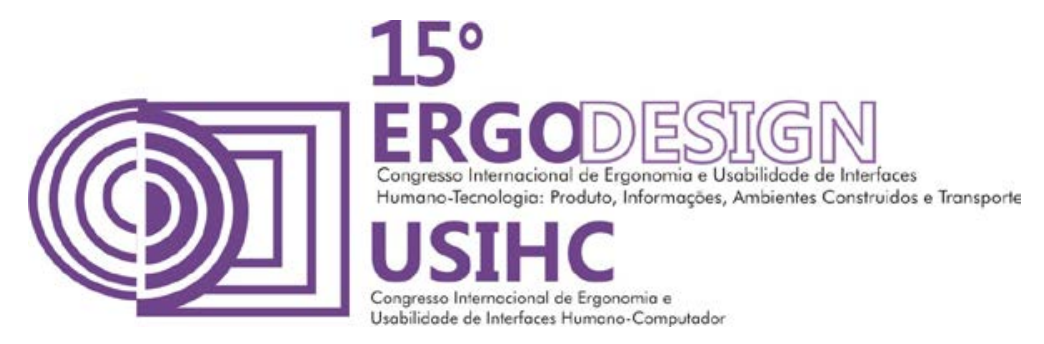

penduradas por uma sustentação tão simples e frágil. A altura de um dos gradeados também era um problema para a vendedora, pois a mesma tinha que realizar um esforço muito grande com o corpo para pegar os objetos que se encontravam expostos na parte superior. A trabalhadora também tinha dores na coluna devido à altura do banquinho em que se sentava, que não possuía nem encosto, nem a altura mínima necessária para um ambiente de trabalho.

Com o objetivo de eliminar todos esses problemas, adicionamos elementos que tem o intuito de proporcionarem uma experiência diária e jornada de trabalho positivas para a nossa usuária. As grades presas por pregos foram substituídas por um balcão móvel com rodinhas, visando facilitar o transporte e a montagem. Dentro do mesmo há compartimentos acessíveis por gavetas, que serão utilizados para guardar o estoque de cases, como também para se anexar a uma cadeira dobrável de madeira, que deu lugar ao pequeno banquinho antes utilizado para se sentar. Na parte superior do produto, agora com altura regularizada em relação às altas grades, localiza-se um expositor retrátil, onde a vendedora deverá expor as cases, e ao final de seu dia de trabalho, poderá retrair as superfícies dobráveis do expositor, visando compactar o espaço quando este não estiver sendo utilizado.

Os benefícios para a usuária alcançados com o redesign são nítidos, houve um melhor arranjo do elementos do sistema, proporcionando praticidade e funcionalidade no armazenamento e na maneira de expor os produtos, e mais conforto no assento.

Para futuros desdobramentos desta pesquisa, sugerimos que seja inserida uma cobertura de encaixe móvel no posto de trabalho, com o intuito de proteger usuário e mercadoria dos problemas naturais como sol ou chuva, e também que no projeto da cadeira sejam introduzidos apoios para braços, mas mantendo sua característica de cadeira dobrável.

\section{REFERÊNCIAS BIBLIOGRÁFICAS}

CHAFFIN, F. B.; ANDERSON, G. B. J.; \& MARTIN, B. J. Biomecânica ocupacional. Belo Horizonte: Ergo, 2001.

FALCÃO, Franciane da Silva, PASCHOARELLIi, Luis Carlos, SILVA, José Carlos Plácido da. Contribuições da Biomecânica para a Análise da Tarefa em Postos de Trabalho: Uma Revisão. Disponível em: http://pessoal.utfpr.edu.br/carlopece/arquivos/Artigo-BiomecanicaAnaliseTarefa.pdf - Data de acesso: 17/07/2014

LIMA, Edmilson Gabriel de. Estudo da Variabilidade das Dimensões Antropométricas a Laser dos Pés Femininos. Disponível em: Http://www.professores.uff.br/cecilia/disciplinas/Texto-Antropometria.pdf Acesso em: 17/07/2014

LÖBACH, Bernd. Design Industrial - Bases para a configuração dos produtos industriais. São Paulo: Editora Blücher, 2001.

MORAES, Anamaria; MONT'ALVÃO, Cláudia. Ergonomia: Conceitos e aplicações. Rio de Janeiro: $2 A B, 2010$.

PANERO, Julius; ZELNIK, Martin. Dimensionamento Humano Para Espaços Interiores. São Paulo: Gustavo Gili, $8^{\circ} \mathrm{ed}, 2013$.

SOARES, M. M.; MORAES, Anamaria de. Apostila de Ergonomia: Princípios, Métodos e Técnicas. UniSESI. Recife, 2005. 